\title{
Face Masks Use and Its Role in Restraining the Spread of COVID-19 Pandemic in Saudi Arabia: Knowledge, Attitude, and Practices Based Cross-Sectional Study
}

\section{OPEN ACCESS}

Edited by:
Atin Adhikari,
Georgia Southern University,
United States

Reviewed by:

Subuhi Sherwani,

University of Hail, Saudi Arabia

Bijaya Kumar Padhi,

Post Graduate Institute of Medical

Education and Research

(PGIMER), India

*Correspondence: Sultan Ayoub Meo

smeo@ksu.edu.sa; sultanmeo@hotmail.com

Specialty section:

This article was submitted to Environmental Health and Exposome a section of the journal

Frontiers in Public Health

Received: 19 November 2021 Accepted: 20 December 2021

Published: 24 January 2022

Citation:

Meo SA, Alqahtani SA, Aljedaie GM, Binmeather FS, AlRasheed RA and Albarrak RM (2022) Face Masks Use and Its Role in Restraining the Spread of COVID-19 Pandemic in Saudi Arabia: Knowledge, Attitude, and Practices Based Cross-Sectional Study. Front. Public Health 9:818520. doi: 10.3389/fpubh.2021.818520

\section{Sultan Ayoub Meo*, Sara A. Alqahtani, Ghada M. Aljedaie, Fatimah S. Binmeather, Renad A. AlRasheed and Raghad M. Albarrak}

Department of Physiology, College of Medicine, King Saud University, Riyadh, Saudi Arabia

Face masks (FM) play a role in limiting the spread of viral infections; despite this, their role is influenced by the population's adherence to wearing the FM. However, the impact on the effectiveness of the FM is variable in various communities. This study aimed to investigate the knowledge, attitude, and practices toward FM use during COVID-19 in Saudi Arabia. This observational "cross-sectional questionnaire-based study was conducted in the Department of Physiology, College of Medicine, King Saud University, Riyadh, Saudi Arabia." The data was collected using an online questionnaire survey from September 8-21, 2021, during the COVID-19 pandemic. The questionnaire was distributed via social media platforms to assess knowledge, attitude, and practices using single choice questions and a five-point Likert scale. Among 1,356, respondents' the rate was 678 (50\%), 207 (30.5\%) were males and 471 (69.5\%) females. Among the participants, Saudi citizens were (649; 95.7\%), with University education (502; 74\%) and were mostly (368; 54.3\%) between 16 and 24 years of age. The participants (384; $56.6 \%, p<0.001$ ) had good knowledge about face masks, and more than half of the respondents, 531 (78.3\%) $(p<0.001)$, showed a positive attitude. Most of the respondents $(477,70.2 \%)$ believed that everyone could use the face mask to minimize the spread of the disease; however $(111 ; 16.4 \%)$ reported that they would not wear a face mask if the government did not recommend wearing it in public places during the COVID-19 pandemic. Saudi citizens have above-average knowledge and optimistic attitudes toward using face masks during the COVID-19 pandemic. The community is convinced about the face masks and believes that face masks play a predominant role in limiting the spread of SARS-CoV-2.

Keywords: face mask, SARS-CoV-2, COVID-19, knowledge, attitude, practice, Saudi Arabia 


\section{INTRODUCTION}

The "Severe Acute Respiratory Syndrome Coronavirus 2 (SARS$\mathrm{CoV}-2)$ " is a highly contagious, challenging, and threatening illness that swiftly spreads worldwide (1). The World health organization (WHO) declared COVID-19 a global pandemic and considered it the fifth pandemic globally since the Spanish flu pandemic in 1918 (2). The SARS-CoV-2 virus is transmitted through direct contact with an infected person (3). As of October 29,2021 , worldwide, the total number of SARS-CoV-2 cases is 245,373,039, and deaths 45,979,421 (2.02\%). However, in Saudi Arabia, which represents a small percentage of the global number of confirmed cases, $548,475(0.22 \%)$, and deaths $8,788(0.01 \%)$ of the global cases and deaths (4).

Since the first case in KSA, the Saudi authorities have managed the COVID-19 pandemic by setting and following protocols to secure their citizens' lives. Which significantly contributes to minimizing and limiting the pandemic around KSA cities (5). Since the beginning of the outbreak, strict policies have been imposed, including lockdown, social distancing, praying at home, suspended all public transport (5). All of that played significantly in shaping the curve of COVID-19 cases and deaths in KSA. However, the authorities started restoring normalcy with time by raising the quarantine procedures, opening some economic and commercial activities, and praying in the mosque and public places, which increased the importance of other preventive methods such as a face mask. Wearing face masks has been imposed in the Kingdom of Saudi Arabia. Face masks play a predominant role in limiting the spread of the viral infection SARS-CoV-2. Face masks are an easy and simple tool to minimize the spread of disease, but the public knowledge, attitude practices, and population's adherence to face masks varied across the countries (6). This study investigates the knowledge, attitude, and practices of using face masks during the COVID-19 pandemic in Riyadh, Saudi Arabia.

\section{SUBJECTS AND METHODS}

This analytical observational "cross-sectional questionnairebased study was conducted in the Department of Physiology, College of Medicine, King Saud University, Riyadh, Saudi Arabia." The present study calculated the sample size to be 601 , to achieve a $96 \%$ confidence level and a $4 \%$ margin of error. An additional $20 \%$ was added to the sample size to ensure a reasonable response rate, resulting in a sample of 721 adults in Riyadh, Saudi Arabia. We have selected 678 (50\%) out of 1,356 responses randomly.

\section{Questionnaire and Data Collection}

The data were collected using an online survey taken from September 8-21,2021, during the COVID-19 pandemic. A wellstructured and pretested questionnaire was developed to achieve the study outcomes per the study's objectives. A research group established the questionnaire after a wide-ranging review of the current literature. The questionnaire items were modified from two previously published studies $(7,8)$. The questionnaire was distributed via social media platforms among the people in
Riyadh, Saudi Arabia, to assess knowledge, attitude, and practices using a five-point Likert scale and single-choice questions. "The questionnaire consisted of five sections," demographic variables, knowledge, attitude, practices, and compliance with wearing the facemasks "and other questions were allied to types and sources of face masks."

Before conducting a pilot test, questions were validated through a senior faculty and these faculty members who were not included in the study. The findings gathered from the pilot assessment were only for the internal consistency reliability of the questionnaire. All the Saudi participants above 16 years of age who had access to the internet were invited. The questionnaire was administered to the participants by a web link through various social media applications.

Eight questions were used on the knowledge aspect, 3 were single choice questions, and 5 were five-point Likert scale. Two questions assessed the attitude, one single-choice and one fivepoint Likert scale. Lastly, four questions were used to evaluate the practice: three single-choice questions and one five-point Likert scale. The internal consistency of the questionnaire was measured by the test-retest reliability, where a coefficient of $\geq 0.8$ demonstrated acceptable internal consistency. We added an Arabic questionnaire and the original English questionnaire to ensure that the participants fully understood the question.

\section{Ethical Approval}

The "Institutional Review Board approved this study, College of Medicine Research Centre, King Saud University, Riyadh, Saudi Arabia” (Ref. E-21-6125).

\section{Statistical Analysis}

The "data were analyzed using the Statistical Package for the Social Sciences (SPSS) version 26 (IBM Corp., Chicago, Illinois, USA)." Univariate analysis was applied after random sampling of respondents to calculate frequency $(n)$ and percentage (\%) for all categorical variables. For the analysis of continuous variables, mean \pm standard deviation (SD) was measured.

There were eight knowledge, two attitude, and four practicebased questions in the questionnaire, and each correct answer was marked one point. The mean score of each component for knowledge, attitude, and practices (KAP) was considered a cut-off value. Respondents' score equal to or higher than the cut-off value was regarded as a good level of each of the three components of KAP, while an individual's score lower than the cut-off value indicated a poor level. To calculate the significance between demographical characteristics with KAP, the Chi-square test for trend and Pearson Chi-square test was used, and a $P \leq$ 0.05 was considered significant.

\section{RESULTS}

\section{Socio-Demographic Characteristics of Study Participants}

Among all 1,356 respondents, 678 (50\%) were randomly selected for the study, including 207 (30.5\%) males and 471 (69.5\%) females. Of all the participants, most of them were Saudi citizens (649; 95.7\%) with University education (502; 74\%) and were 
TABLE 1 | Demographic characteristics, level of education, employment, and income status of 678 subjects.

\begin{tabular}{|c|c|}
\hline Characteristics & Summary statistics $N(\%)$ \\
\hline \multicolumn{2}{|l|}{ Age (years) } \\
\hline $16-24$ & 368 (54.3) \\
\hline $25-34$ & $113(16.7)$ \\
\hline $35-44$ & $74(10.9)$ \\
\hline $45-54$ & $90(13.3)$ \\
\hline $55-64$ & $29(4.3)$ \\
\hline $65-74$ & $2(3)$ \\
\hline 75 and Above & $2(3)$ \\
\hline \multicolumn{2}{|l|}{ Gender } \\
\hline Male & 207 (30.5) \\
\hline Female & $471(69.5)$ \\
\hline \multicolumn{2}{|l|}{ Education Status } \\
\hline Primary School & $4(6)$ \\
\hline Elementary School & $6(9)$ \\
\hline High School & $105(15.5)$ \\
\hline University & $502(74.0)$ \\
\hline Postgraduate & $53(7.8)$ \\
\hline Other & $8(1.2)$ \\
\hline \multicolumn{2}{|l|}{ Employment status } \\
\hline Student & 325 (47.9) \\
\hline Employed & $199(29.4)$ \\
\hline Unemployed & $79(11.7)$ \\
\hline Retired & $50(7.4)$ \\
\hline Other & $25(3.7)$ \\
\hline \multicolumn{2}{|l|}{ Nationality } \\
\hline Saudi & $649(95.7)$ \\
\hline Non-Saudi & $29(4.3)$ \\
\hline \multicolumn{2}{|l|}{ Income (SR)/month } \\
\hline Below 5,000 SAR & $99(14.6)$ \\
\hline $5,001-10,000$ SAR & $138(20.4)$ \\
\hline 10,001-20,000 SAR & $154(22.7)$ \\
\hline $20,001-40,000$ SAR & $136(20.1)$ \\
\hline 40,001-60,000 SAR & $57(8.4)$ \\
\hline Greater than 60,001 & $94(13.9)$ \\
\hline
\end{tabular}

mostly $(368 ; 54.3 \%)$ between 16 and 24 years of age. The average household income of all the subjects was between 10,001 and 20,000 SAR per month (Table 1).

\section{Knowledge, Attitudes, and Practices Related to Face Mask Use}

Among all the participants, a large number of individuals (384; 56.6\%; $p<0.001$ ) had a good knowledge score of face masks used with a mean score of $6.2 \pm 1.2(p<0.001)$ (Table 2$)$. The mean score of attitudes toward face mask use was $0.8 \pm 0.47(p$ $<0.001)$, and more than half of the respondents, $531(78.3 \%)$ $(p<0.001)$, showed a positive attitude. The study observed a good practice score $(460 ; 67.8)(p<0.001)$ in the majority of the participants, with an average score of $2.7 \pm 0.085(p<0.001)$. Most of the respondents $(476 ; 70.2 \%)$ believed that everyone
TABLE 2 | Knowledge, attitudes, and practices of 678 respondents related to face mask use and reuse.

\begin{tabular}{lc}
\hline Items & Mean \pm SD or n (\%) \\
\hline Knowledge score & $6.2 \pm 1.2(1-8)$ \\
Knowledge score group & $294(43.4)$ \\
Poor & $384(56.6)$ \\
Good & $0.8 \pm 0.47(0-2)$ \\
\hline Attitude score & \\
Attitude score group & $147(21.7)$ \\
Negative & $531(78.3)$ \\
Positive & $2.7 \pm 0.085(0-4)$ \\
\hline Practice score & $218(32.2)$ \\
Poor & $460(67.8)$ \\
Good & $197(29.1)$ \\
\hline Why reuse face mask the mask is still clean (there is & \\
no visible dirt) & $66(9.7)$ \\
Reusing the face mask in accordance with the & $29(4.3)$ \\
manufacturer's recommendation & $361(53.2)$ \\
Saving money & $477(70.2)$ \\
I do not reuse my face mask & $29.7)$ \\
Face masks minimize the disease spread & \\
Other & \\
\hline SO & \\
\hline
\end{tabular}

$S D$, standard deviation.

could use the face mask to minimize the spread of the disease. However, 149 (22\%) participants were unaware of who could use it, and a significant difference was observed among males and females $(p=0.09)$. A significantly greater number $(p=$ 0.02) of participants (females:282, and males:101) reported that children under 5 years of age don't need to wear masks in case of severe shortage, while fewer respondents had other concepts (Figure 1).

Out of all the individuals, only a few $(111 ; 16.4 \%)$ reported that they would not wear a face mask if the government did not recommend wearing it in public places during the COVID19 pandemic. However, most of them showed compliance with the face mask and preferred to use it despite the government's non-recommendations (Figure 2). The majority of the males and females $(350 ; 51.6 \%)$ follow good hygiene practices and always wash their hands after removal of face mask $(p=0.02)$ with alcohol-based hand rub $(248 ; 36.6 \% ; p=0.3)$ or soap and water $(n=231 ; 34.1 \% ; p=0.06)$ however, only $29.4 \%(p=0.1)$ of the respondents were not in the practice of washing hands after face mask removal. The study also observed that among male and females $88.8 \%(602 ; p=0.70)$ of the respondents use surgical masks, and only $2.4 \%(n=16)$ use N95 $(p=0.627)$ (Figure 3).

Of the all males and females face mask users, 296 (43.7\%) reported that they reused face masks and had a perception that the face mask is still clean if no visible dirt $(196 ; 29.9 \%$; $p=0.018)$, while some of them $(66 ; 9.7 \% ; p=0.084)$ reuse it according to the manufacturer recommendations. Although, most of the study population $(382 ; 56 ; 1 \% ; p=0.061)$ showed the good practice of not wearing the same mask again (Table 2). 


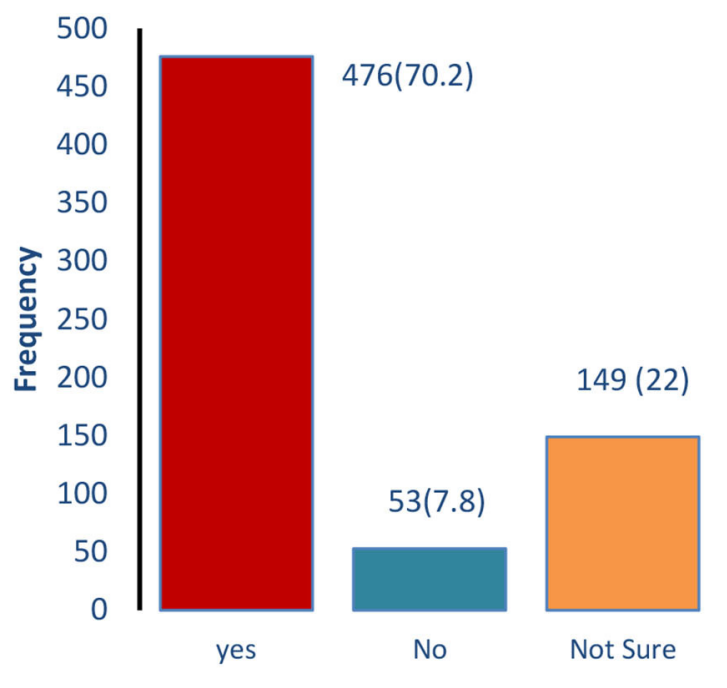

Every one can wear face mask

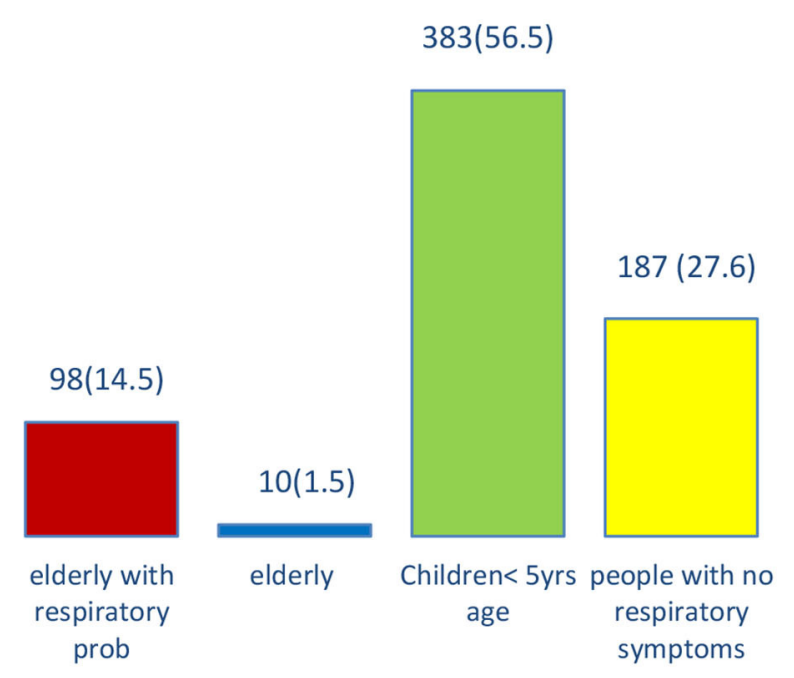

Who don't need to wear mask in case of shortage

FIGURE 1 | Participant's knowledge of wearing the face mask.

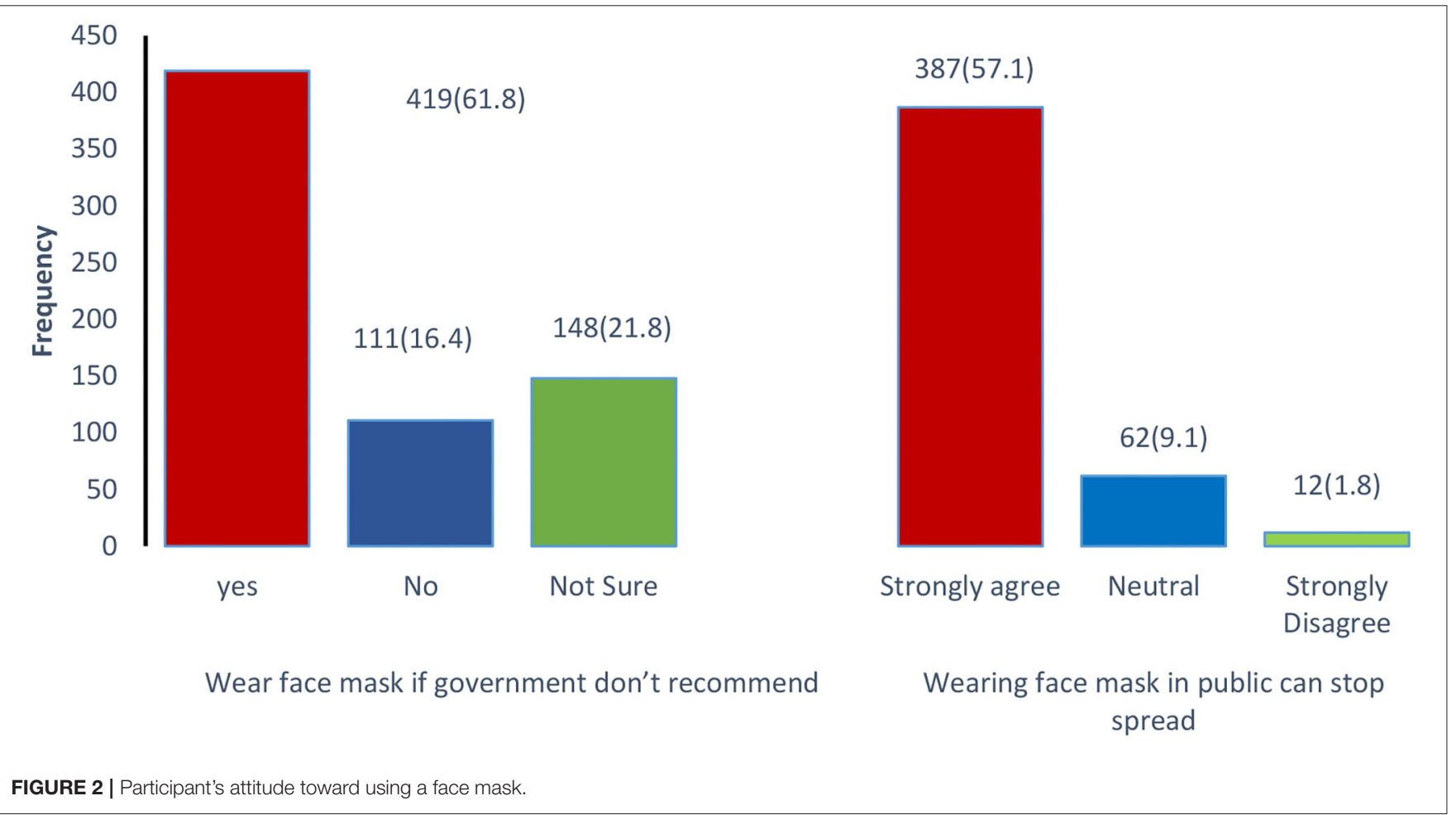

Factors Affecting Knowledge, Attitudes, and Practices Related to Face Mask Use

There was no significant difference in knowledge among various age groups and nationalities. However, a significant difference was observed in the different income groups of respondents $(p=0.003)$. Gender variations $(p=0.021)$ and education level $(p=0.04)$ significantly changed the attitudes toward wearing a face mask, and a positive attitude was observed primarily on University students. There was a significant difference in the practices of using a face mask in different 


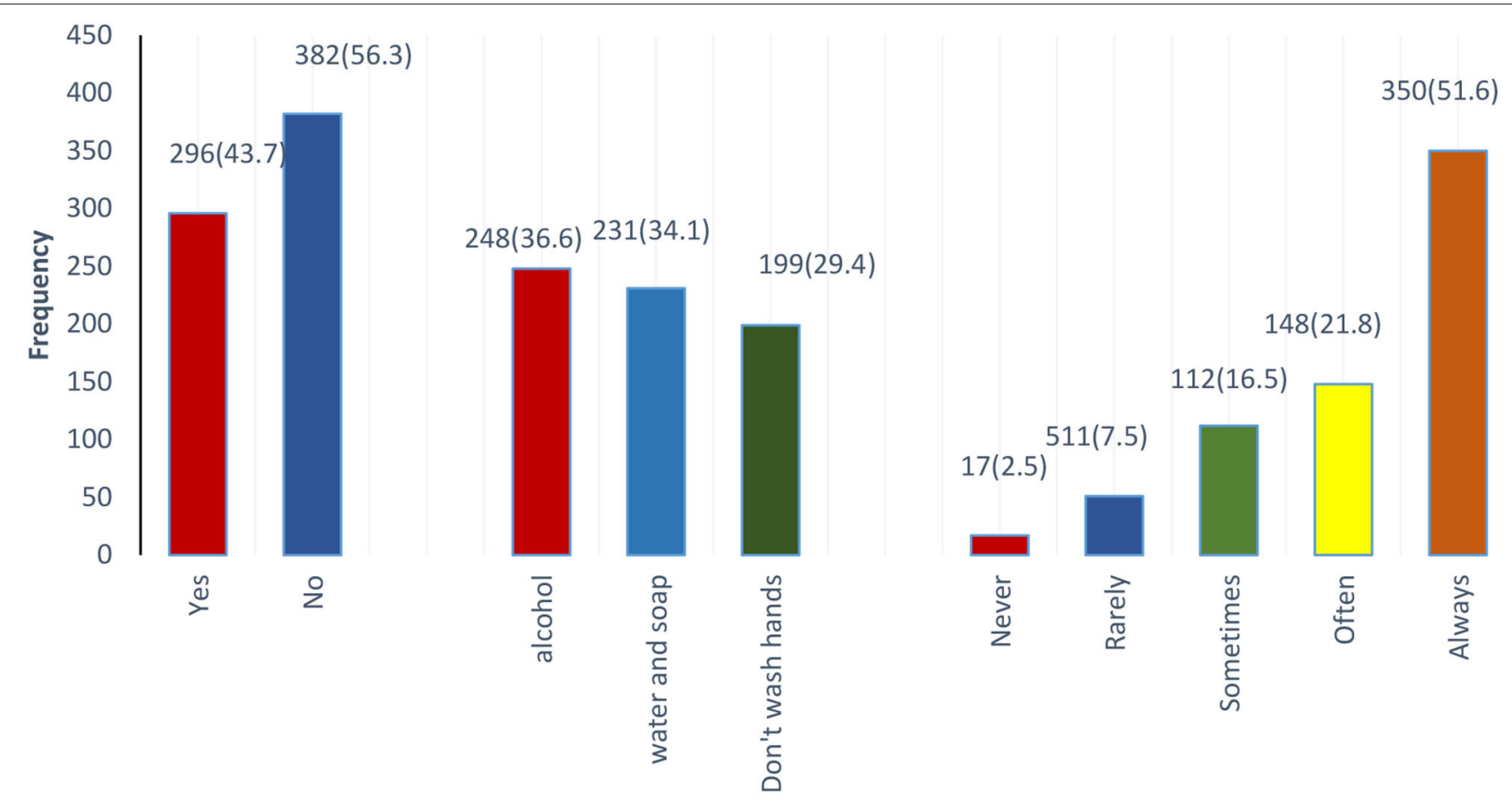

Reuse of same face mask Washiing after touching face mask Frequency of washing hand after face mask removal

FIGURE 3 | Participant's practice using a face mask.

age groups $(P<0.001)$, an education level $(p=0.04)$, and income group $(p=0.029)$, while there was no effect of gender and nationality on the practice of using face masks (Table 3).

\section{DISCUSSION}

Worldwide, many countries have investigated several physiological and public health measures to mitigate the spread of COVID-19. The most frequently implemented action was face masks (9). Physiological preventive measures and public health strategies played a significant role in combatting infectious diseases, including the COVID-19 pandemic. These preventative measures are handwashing/sanitizing, social distance, avoiding public gatherings, and wearing a face mask (10). Understanding the predictors of increased adherence to these public health measures is essential for the COVID-19 and future pandemics. In this study, most participants had good knowledge about face masks and showed a positive attitude. The respondents believed that everyone could use the face mask. Saudi citizens have above-average knowledge and optimistic attitudes toward the use of face masks during the COVID-19 pandemic. The community is convinced about using face masks and believes that face masks play a predominant role in limiting the spread of the viral infection, SARS-CoV-2.

In this study, the use of face masks was significantly linked with age, gender, region, education, and employment. The young adults (16-34 years), male, higher education, and students showed better compliance than other groups. Similar findings have also been reported by $\mathrm{Li}$ et al. face masks use with social distancing could effectively minimize the COVID-19 risk in the community (11). Despite improper compliance, it is a fact that using any face mask decreases the disease exposure and the risk of infection (12). It has also been demonstrated that the community benefit of using a face mask depends on compliance and early use during the pandemic, together with hand hygiene (13).

A study on a Malaysian community has reported an overall knowledge rate of $80.5 \%$, and most participants $(83.1 \%)$ demonstrated positive attitudes toward preventing COVID19 (11). In the present study, over $56.6 \%$ of the participants had a good knowledge of face masks, and more than half of the respondents, $78.3 \%$, showed a positive attitude. The study observed a good practice score of $67.8 \%$ in the majority of the participants, with an average score. Most of the respondents, $70.2 \%$, believed that everyone could use the face mask to minimize the spread of the disease. Sikakulya et al. (14) reported that about $60 \%$ of the participants had adequate knowledge on the use of face masks among the respondents; about $83.4 \%$ believed that a face mask could protect against COVID-19. The majority of respondents (95.2\%) agreed that wearing face masks in public places was essential to protect themselves against COVID-19.

Alremeithi et al. (15) explored the population's knowledge, attitude, and practice toward COVID-19 in the United Arab 
TABLE 3 | Association of knowledge, attitude, and practices of face mask use.

\begin{tabular}{|c|c|c|c|c|c|c|}
\hline \multirow[t]{2}{*}{ Characteristics } & \multicolumn{2}{|c|}{ Knowledge } & \multicolumn{2}{|c|}{ Attitude } & \multicolumn{2}{|c|}{ Practice } \\
\hline & Good $N(\%)$ & Poor N (\%) & Positive $N(\%)$ & Negative $N(\%)$ & Good N (\%) & Poor N (\%) \\
\hline Age & \multicolumn{2}{|c|}{$P=0.508^{a}$} & \multicolumn{2}{|c|}{$P=0.564^{a}$} & \multicolumn{2}{|c|}{$p<0.001^{a}$} \\
\hline $16-24$ & $204(30.1)$ & $164(24.2)$ & 288 (42.5) & $80(11.8)$ & $229(33.8)$ & 139 (20.5) \\
\hline $25-35$ & 65 (19.6) & $48(7.1)$ & 85 (12.5) & $28(4.1)$ & $82(12.1)$ & 31 (4.6) \\
\hline $35-44$ & $45(6.6)$ & $29(4.3)$ & $62(9.1)$ & $12(1.8)$ & $52(7.7)$ & 22 (3.2) \\
\hline $45-54$ & $46(6.8)$ & $44(6.5)$ & 67 (9.9) & $23(3.4)$ & $66(9.7)$ & $24(3.5)$ \\
\hline$>55$ & $24(3.5)$ & $9(1.3)$ & $29(4.3)$ & $4(0.6)$ & 31 (4.6) & $2(0.3)$ \\
\hline Gender & \multicolumn{2}{|c|}{$P=0.835^{\mathrm{b}}$} & \multicolumn{2}{|c|}{$p=0.0216^{\star b}$} & \multicolumn{2}{|c|}{$p=0.250^{b}$} \\
\hline Male & $116(17.1)$ & $91(13.4)$ & $156(23.0)$ & $51(7.5)$ & $134(19.8)$ & 73 (10.8) \\
\hline Female & 268 (39.5) & 203 (29.9) & 375 (55.3) & $96(14.2)$ & $326(48.1)$ & 145 (21.4) \\
\hline Nationality & \multicolumn{2}{|c|}{$p=0.192^{b}$} & \multicolumn{2}{|c|}{$p=0.430^{b}$} & \multicolumn{2}{|c|}{$p=0.895^{b}$} \\
\hline Saudi & 368 (54.3) & $281(41.4)$ & $510(75.2)$ & 139 (20.5) & $440(64.9)$ & $209(30.8)$ \\
\hline Non Saudi & $6(2.4)$ & $13(1.9)$ & $21(3.1)$ & $8(1.2)$ & 20 (2.9) & $9(1.3)$ \\
\hline Education & \multicolumn{2}{|c|}{$p=0.518^{a}$} & \multicolumn{2}{|c|}{$p=0.040^{\mathrm{aa}}$} & \multicolumn{2}{|c|}{$p=0.04^{\star a}$} \\
\hline Secondary and & 68 (10.0) & $47(6.9)$ & 91 (13.3) & $24(3.4)$ & $86(12.7)$ & $29(4.3)$ \\
\hline \multicolumn{7}{|l|}{ Higher Secondary } \\
\hline University & $279(41.2)$ & 223 (32.9) & $394(58.1)$ & 108 (15.9) & $330(48.7)$ & $172(25.4)$ \\
\hline Postgraduate & $37(5.5)$ & $24(3.6)$ & $39(6.8)$ & $15(2.2)$ & $44(6.5)$ & $17(2.5)$ \\
\hline \multicolumn{7}{|l|}{ and others } \\
\hline Income & \multicolumn{2}{|c|}{$p=0.003^{\star a}$} & \multicolumn{2}{|c|}{$p=0.508$} & \multicolumn{2}{|c|}{$p=0.029^{\star a}$} \\
\hline Below 5,000 & 43 (6.3) & 56 (8.3) & $84(12.4)$ & $15(2.2)$ & $76(11.2)$ & $23(3.4)$ \\
\hline $5,001-10,000$ & $76(11.2)$ & $62(9.1)$ & 108 (15.9) & $30(4.4)$ & $98(14.5)$ & $40(5.9)$ \\
\hline $10,001-20,000$ & $86(12.7)$ & $68(10.0)$ & $116(17.1)$ & $38(5.6)$ & 104 (15.3) & $50(7.4)$ \\
\hline $20,001-40,000$ & $82(12.1)$ & $54(8.0)$ & 105 (15.5) & 31 (4.6) & $84(12.4)$ & $52(7.7)$ \\
\hline $40,001-60,000$ & $40(5.9)$ & $17(2.5)$ & $40(5.9)$ & $17(2.5)$ & 37 (5.5) & $20(2.9)$ \\
\hline Above 60,000 & $57(8.4)$ & $37(5.5)$ & 78 (911.5) & $16(2.4)$ & $61(9.0)$ & $33(4.9)$ \\
\hline
\end{tabular}

*Significant: $P<0.05$.

${ }^{a}$ Chi-Square for trend.

${ }^{b}$ Pearson Chi-Square.

Participants 678, Chi-square test, was performed between trend with demographic characteristics.

Emirates. The authors reported that the knowledge was linked with higher education, and there was a positive association between the level of education and SARS-COV-2 infection knowledge. Larebo et al. (16) demonstrated that the student's overall knowledge was $29.2 \%$, attitude $88.1 \%$, and their practice was $89.5 \%$. The students from the college natural and computational sciences have good knowledge independently associated with face mask utilization. While comparing with other studies, authors found that face masks usage knowledge was low, but the attitudes and practices were high.

Sugimura et al. (17) conducted a study on the relative risk of COVID-19 for mask users vs. non-mask users. In this study, about 800 participants were included; $53 \%$ wore masks. The nonmask users were infected at $16 \%$, while mask users were infected at $7.1 \%$. People using the face mask are $60 \%$ less likely to be infected with COVID-19 than non-mask wearers (17). In another study, findings also suggest that face mask use in public could help in mitigating the spread of COVID-19 (18). Face masks are highly essential to minimize the spread of infectious diseases such as the COVID-19 pandemic. The primary mechanism behind the use of face masks and their role in reducing the spread of SARS-CoV-2 disease is that face masks can reduce the entry of small tiny particles and air pollutants. The cluster of reports indicates that respiratory transmission is the primary source of transmission risk of SARS-CoV-2 (3). However, gastrointestinal $(19,20)$ and ocular $(21)$ sources also transmit the diseases. Once these contaminated droplets and particles are on any surface, the air pollutants, mainly the particulate matter PM2.5, can easily carry and transport from region to region and easily contaminate an individual. A series of reports are available on the air pollutants and their role in spreading SARS-CoV-2 cases by Meo et al. (22-24). The face masks could minimize the entry of contaminants into the respiratory and oral cavity, minimizing the spread of the disease. We believe using face masks to reduce the spread of the diseases is essential for both the public and policymakers to combat against COVID-19 pandemic. 


\section{STRENGTHS AND LIMITATIONS}

This study's strength is that the findings are based on an appropriate sample size during the COVID-19 pandemic in Saudi Arabia. Second: the questionnaire survey was offered in Arabic and English languages, able to reach the large segments of the society containing both male and females population of the country. This study has some limitations. The social media group users are mainly the young and middle-aged generation, so the old age group participants may not represent this study appropriately. The second limitation is that the elderly and daily basis laborers could have been underestimated in our sample. The third limitation is that self-reported questions may not assess the findings appropriately; hence, further studies can be conducted to validate the results further and clarify the casual relationship to improve the population knowledge attitude and practice regarding the implementation of evidence-based effective physiological and public health policies and procedures as face masks.

\section{CONCLUSIONS}

The results revealed good compliance of people in wearing face masks in public and workplaces in Saudi Arabia. The majority of the participants had good knowledge about face masks, and about two-thirds of respondents showed a positive attitude. Most of the respondents believed that everyone could use the face mask; however, a limited number reported that they would not wear it if the government did not recommend wearing it in public places during the COVID-19 pandemic. Saudi citizens

\section{REFERENCES}

1. Meo SA, Alkhalifah JM, Alshammari NF, Alnufaie WS. Comparison of generalized anxiety and sleep disturbance among frontline and second-line healthcare workers during the COVID-19 pandemic. Int J Environ Res Public Health. (2021) 18:5727. doi: 10.3390/ijerph18115727

2. Agrawal A, Gindodiya A, Deo K, Kashikar S, Fulzele P, Khatib N. A comparative analysis of the Spanish flu 1918 and COVID19 pandemics. Open Public Health J. (2021) 14(Suppl-1):128-34. doi: 10.2174/1874944502114010128

3. Meyerowitz EA, Richterman A, Gandhi RT, Sax PE. Transmission of SARSCoV-2: a review of viral, host, and environmental factors. Ann Intern Med. (2021) 174:69-79. doi: 10.7326/M20-5008

4. World Health Organization. Coronavirus (COVID-19) Dashboard. (2021). Available online at: https://covid19.who.int/ (accessed October 29, 2021).

5. Meo SA. COVID-19 pandemic: Saudi Arabia's role at national and international levels. J Diabetes Sci Technol. (2020) 14:758-9. doi: $10.1177 / 1932296820930068$

6. Feng S, Shen C, Xia N, Song W, Fan M, Cowling BJ. Rational use of face masks in the COVID-19 pandemic. Lancet Respir Med. (2020) 8:434-6. doi: 10.1016/S2213-2600(20)30134-X

7. Al Naam YA, Elsafi SH, Alkharraz ZS, Alfahad OA, Al-Jubran KM, Al Zahrani EM. Community practice of using face masks for the prevention of COVID-19 in Saudi Arabia. PLoS ONE. (2021) 2:e0247313. doi: 10.1371/journal.pone.0247313

8. Duong MC, Nguyen HT, Duong BT. A cross-sectional study of knowledge, attitude, and practice towards face mask use amid the COVID-19 pandemic have above-average knowledge and optimistic attitudes toward the use of face masks during the COVID-19 pandemic. The community is convinced about the use of face masks and believes that face masks play a significant role in limiting the spread of the SARS-CoV-2 infection.

\section{DATA AVAILABILITY STATEMENT}

The raw data supporting the conclusions of this article will be made available by the authors, without undue reservation.

\section{ETHICS STATEMENT}

The studies involving human participants were reviewed and approved by Institutional Review Board approved this study, College of Medicine Research Centre, King Saud University, Riyadh, Saudi Arabia (Ref. E-21-6125). Written informed consent to participate in this study was provided by the participants' legal guardian/next of kin.

\section{AUTHOR CONTRIBUTIONS}

SM: project supervision, writing-review, and editing. SA, GA, FB, RAA, and RMA: data collection, checking, entry, and analysis. All authors contributed to the article and approved the submitted version.

\section{ACKNOWLEDGMENTS}

We thank the Researchers supporting project number (RSP2021/47), King Saud University, Riyadh, Saudi Arabia. amongst University students in Vietnam. J Community Health. (2021) 46:97581. doi: 10.1007/s10900-021-00981-6

9. Mitze T, Kosfeld R, Rode J, Wälde K. Face masks considerably reduce COVID-19 cases in Germany. Proc Natl Acad Sci USA. (2020) 117:32293-301. doi: 10.1073/pnas.2015954117

10. Chiu NC, Chi H, Tai YL, Peng CC, Tseng CY, Chen CC, et al. Impact of wearing masks, hand hygiene, and social distancing on influenza, enterovirus, and all-cause pneumonia during the coronavirus pandemic: retrospective national epidemiological surveillance study. J Med Internet Res. (2020) 22:e21257. doi: 10.2196/21257

11. Li T, Liu Y, Li M, Qian X, Dai SY. Mask or no mask for COVID19: A public health and market study. PLoS ONE. (2020) 15:e0237691. doi: 10.1371/journal.pone. 0237691

12. Van der Sande M, Teunis P, Sabel R. Professional, and homemade face masks reduce exposure to respiratory infections among the general population. PLoS ONE. (2008) 3:e2618. doi: 10.1371/journal.pone.00 02618

13. MacIntyre CR, Chughtai AA. A rapid systemic review of the efficacy of face masks and respirators against coronaviruses and other respiratory transmissible viruses for the community, health workers, and sick patients. Int J Nurs Stud. (2020) 108:103629. doi: 10.1016/j.ijnurstu.2020.103629

14. Sikakulya FK, Ssebuufu R, Mambo SB, Pius T, Kabanyoro A, Kamahoro E, et al. Use of face masks to limit the spread of the COVID-19 among western Ugandans: knowledge, attitude and practices. PLoS ONE. (2021) 16:e0248706. doi: 10.1371/journal.pone.0248706

15. Alremeithi HM, Alghefli AK, Almadhani $\mathrm{R}$ et al. Knowledge, attitude, and practices toward SARS-COV-2 infection in the United Arab Emirates 
population: an online community-based cross-sectional survey. Front Public Health. (2021) 9:687628. doi: 10.3389/fpubh.2021.687628

16. Larebo YM, Abame DE. Knowledge, attitudes, and practices of face mask utilization and associated factors in COVID-19 pandemic among Wachemo University Students, Southern Ethiopia: a cross-sectional study. PLoS ONE. (2021) 16:e257609. doi: 10.1371/journal.pone.0257609

17. Sugimura M, Chimed-Ochir O, Yumiya Y, Ohge H, Shime N, Sakaguchi T, et al. The association between wearing a mask and COVID-19. Int J Environ Res Public Health. (2021) 18:9131. doi: 10.3390/ijerph18179131

18. Lyu W, Wehby GL. Community use of face masks and COVID-19: evidence from a natural experiment of state mandates in the US. Health Aff. (2020) (8):1419-25. doi: 10.1377/hlthaff.2020.00818

19. Gu J, Han B, Wang J. COVID-19: gastrointestinal manifestations and potential fecal-oral transmission. Gastroenterology. (2020) 158:1518-9. doi: 10.1053/j.gastro.2020.02.054

20. Wang $\mathrm{W}, \mathrm{Xu} \mathrm{Y}$, Gao R, Lu R, Han $\mathrm{K}, \mathrm{Wu}$ G, et al. Detection of SARSCoV-2 in different types of clinical specimens. JAMA. (2020) 323:1843-4. doi: 10.1001/jama.2020.3786

21. Deng W, Bao L, Gao H, Xiang Z, Qu Y, Song Z, et al. Ocular conjunctival inoculation of SARS-CoV-2 can cause mild COVID-19 in rhesus macaques. Nat Commun. (2020) 11:4400. doi: 10.1038/s41467-020-18149-6

22. Meo SA, Abukhalaf AA, Alessa OM. et al. Effect of environmental pollutants $\mathrm{PM}_{2.5}, \mathrm{CO}, \mathrm{NO}_{2}$, and $\mathrm{O}_{3}$ on the incidence and mortality of SARS-CoV-2 infection in five regions of the USA. Int J Environ Res Public Health. (2021) 18:7810. doi: 10.3390/ijerph18157810

23. Meo SA, Almutairi FJ, Abukhalaf AA, Alarifi AS, Sami W, Klonoff DC. Sandstorm and its effect on particulate matter $\mathrm{PM}_{2.5}$, carbon monoxide, nitrogen dioxide, ozone pollutants, and SARS-CoV-2 cases and deaths. Sci Total Environ. (2021) 795:148764. doi: 10.1016/j.scitotenv.2021.148764

24. Meo SA, Adnan Abukhalaf A, Sami W, Hoang TD. Effect of environmental pollution PM25, carbon monoxide, and ozone on the incidence and mortality due to SARS-CoV-2 infection in London, United Kingdom. J King Saud Univ Sci. (2021) 33:101373. doi: 10.1016/j.jksus.2021.1 01373

Conflict of Interest: The authors declare that the research was conducted in the absence of any commercial or financial relationships that could be construed as a potential conflict of interest.

Publisher's Note: All claims expressed in this article are solely those of the authors and do not necessarily represent those of their affiliated organizations, or those of the publisher, the editors and the reviewers. Any product that may be evaluated in this article, or claim that may be made by its manufacturer, is not guaranteed or endorsed by the publisher.

Copyright (c) 2022 Meo, Alqahtani, Aljedaie, Binmeather, AlRasheed and Albarrak. This is an open-access article distributed under the terms of the Creative Commons Attribution License (CC BY). The use, distribution or reproduction in other forums is permitted, provided the original author(s) and the copyright owner(s) are credited and that the original publication in this journal is cited, in accordance with accepted academic practice. No use, distribution or reproduction is permitted which does not comply with these terms. 